\title{
A CRIAÇÃO E A RECRIAÇÃO CAMPONESA NO TERRITÓRIO CANTUQUIRIGUAÇU PARANÁ, POR MEIO DA LUTA E DA RESISTÊNCIA
}

\section{ARTIGO ORIGINAL}

MORAES, Vitor De ${ }^{1}$

MARTINS, Fernando José ${ }^{2}$

MORAES, Vitor De. MARTINS, Fernando José. A criação e a recriação Camponesa no Território Cantuquiriguaçu Paraná, por meio da luta e da resistência. Revista Científica Multidisciplinar Núcleo do Conhecimento. Ano 05, Ed. 08, Vol. 09, pp. 104121. Agosto de 2020. ISSN: 2448-0959, Link de acesso: https://www.nucleodoconhecimento.com.br/educacao/recriacao-camponesa

\section{RESUMO}

O referido trabalho apresenta o território Cantuquiriguaçu da meso região centro e oeste do estado do Paraná, trazendo a luz do conhecimento científico, a luta, a resistência camponesa e as dimensões que interferem na produção da vida e no desenvolvimento integral do Território. Explicitando os caminhos dentro de uma conjuntura que modifica essa realidade estrutural da vida dos sujeitos que compõe o território. O resultado da pesquisa é oriundo da abstração da realidade, por meio das metodologias utilizadas: qualitativa, bibliográfica e participante. Foram analisados elementos e dimensões que demonstram avanços e retrocessos, utilizando depoimentos dos agricultores do campesinato e do agronegócio e os dados estatísticos dos Censos IBGE, 1996, 2000, 2010, e a evolução desses, até o Censo

\footnotetext{
${ }^{1}$ Mestre em Geografia - UNESP/SP. Mestre em Educação pela UNICENTRO PR, Especialista em Educação do Campo pela UFPR, Especialista em Educação Matemática pela UNICENTRO - PR.

2 Orientador. Doutorado em Sociedade Cultura e Fronteiras.
} 
agropecuário de 2017, qualitativamente, na interfase com a práxis dos Movimentos Sociais Populares do Campo (MSPC) e o Conselho de Desenvolvimento Territorial (CONDETEC), no território Cantuquiriguaçu Paraná. Este trabalho de pesquisa é parte de pesquisa de Doutorado em Sociedade, Cultura e Fronteiras. De antemão, podemos afirmar que existe a criação e a recriação camponesa no Território Cantuquiriguaçu por meio da luta e da resistência.

Palavras-chave: luta, resistência, território Cantuquiriguaçu.

\section{INTRODUÇÃO}

Este estudo analítico teve como objetivo apresentar a realidade que estamos vivendo, de modo especial verificar a realidade configurada no Território Cantuquiriguaçu, meso região centro e oeste do estado do Paraná. A formação territorial é o resultado de um processo cruel do genocídio indígena, de escravidão, servidão e de outro lado de uma elite agrária concentradora de terras, riquezas e poder junto aos governantes. O trato desigual com a terra, levou milhares de camponesas a abandonarem o campo e morarem atualmente em favelas e bairros pobres. Esse modelo elitizado e atrasado provocou o atual caos social, econômico e desigual do país.

O referido trabalho abstraiu da realidade, a criação e a recriação camponesa apesar das conflitualidades causadas pela imposição do modelo capitalista hegemônico. A análise aqui colocada foi a partir da totalidade das relações e, das inferências que modificaram as formas de vida, de uso e de ocupação do território, as quais de forma antagônicas intensificaram a luta de classe. De um lado os camponeses (as), produzindo alimentos, na resistência e luta pela terra, de outro o agronegócio por meio de monoculturas e latifúndios que visam apenas produção de commodities, por meio da concentração de terras e uso intensivo de agrotóxicos. 


\section{LUTAS E RESISTÊNCIAS: MARCOS DO POVO CANTUQUIRIGUAÇUENSE}

O Território Cantuquiriguaçu compreende os municípios de Laranjeiras do Sul, Nova Laranjeiras, Porto Barreiro, Rio Bonito do Iguaçu, Candói, Foz do Jordão, Reserva do Iguaçu, Pinhão, Marquinho, Goioxim, Cantagalo, Guaraniaçu, Diamante do Sul, Campo Bonito, Espigão Alto do Iguaçu, Ibema, Catanduvas, Três Barras do Paraná, Quedas do Iguaçu e Virmond.

De acordo pesquisas de Pontarolo, (2012), O Território Cantuquiriguaçu está marcado pelo genocídio e massacre dos povos indígena que habitavam estas terras. Território que esteve submetido a permanentes diligências, que exploravam minérios em especial o ouro e demais recursos naturais, deste início da década de 1770 . No entanto, sem sucesso, em relação à resistência do povo Kaingang. Os Kaingang atacaram e mataram vários soldados que estava a serviço da Coroa Portuguesa, conforme está nas Cartas Régias dos anos de 1808 e 1809, Pontarolo, (2012), a coroa tinha como objetivo povoar os campos e civilizar os "índios bárbaros", atendendo também as oligarquias e comerciantes das regiões de Castro e Curitiba que visavam a expansão de seus negócios. Com o objetivo de encontrar metais preciosos, a coroa visava dominar oficialmente o território, destruindo os territórios indígenas e assim protegendo as pessoas que estivessem a serviço da Coroa Portuguesa. Inicialmente as terras foram distribuídas em sesmarias no Centro-Sul Paranaense de acordo com o tamanho estabelecido pela Coroa Portuguesa. A forma de povoação do território também ocorreu por meio do envio de criminosos condenados ao degredo. "Através da inclusão contínua de prisioneiros, realizava os interesses de recriação de uma sociedade expansiva, hierárquica e baseada na manutenção de cadeias de dependência pessoal entre os novos moradores" (PONTAROLO, 2012, P. 37). O Controle do território foi consumado pelas oligarquias locais em conjunto com a coroa. "As terras passaram então a ser adquiridas através das posses ou ocupação, estabelecendo-se latifúndios maiores que os formados pelas sesmarias" (ABREU, 1981, p. 53). A pecuária passou a ser a principal cultura com o uso de extensas áreas de terras. A partir de meados do século XIX até o início do século XX, a extração e o 
beneficiamento da erva mate (Ilexparaguariensis), despontou como uma das principais atividades econômicas da região. A erva-mate era um produto que alcançava alto preço no mercado externo e a sua exportação era monopólio dos Jesuítas até meados do século XVIII (ROOS, p.127, 2015).

Essa configuração da região Centro Sul do Estado do Paraná foi construída na contradição e no conflito permanente. Basta observar a luta histórica dos povos do campo sem-terra e dos quilombolas, dos povos e comunidades tradicionais, dos faxinalenses. Povos que lutam na reterritorialização de seus territórios, mantê-los e se possível ampliá-los. A base econômica do território estava alicerçada no seu início na expropriação dos recursos naturais, exploração dos habitantes nativos e da mão de obra escrava, atividades de caráter extensivo, extrativismo, exploração das vastas áreas naturais e de florestas nativas. "De forma geral, o desenvolvimento da região esteve sempre associado à exploração de algum recurso da natureza, consumada de forma predatória e rudimentar" (IPARDES, 2004, p. 23). A conformação do território deve-se ao empobrecimento histórico causado pela forma como a elite dominante previu o desenvolvimento. Deve-se, sobretudo, considerar o "processo histórico que atuou na conformação da base produtiva, estabelecendo a dinâmica econômica e as relações de poder, que conjuntamente, formaram a organização da sociedade no Centro-Sul Paranaense" (ROOS, p.134, 2015).

O território passou a denominar-se Cantuquiriguaçu em 07 de agosto de 1984. Valmir Gomes da Rocha Loures, prefeito de Laranjeiras do Sul e João Ceccura, prefeito de Palmital, fundaram a Associação dos Municípios da Cantuquiriguaçu. João Ceccura como primeiro presidente. $\mathrm{O}$ nome do território foi escolhido devido aos municípios associados se localizarem nos vales dos rios Cantu, Piquiri e Iguaçu (MORAES, 2013, p 98). Em 2008 o Território passou a ser denominado de Território da Cidadania, pelo Ministério de Desenvolvimento Agrário, (MDA, 2013).

Os Territórios da Cidadania tem como objetivos promover o desenvolvimento econômico e universalizar programas básicos de cidadania por meio de uma estratégia de desenvolvimento territorial sustentável. A participação social e a integração de ações entre Governo 
Federal, Estados e municípios são fundamentais para a construção dessa estratégia (BRASIL, 2013, p. 1).

Dentre as conquistas no Território Cantuquiriguaçu, vale destacar a conquista da terra, de forma tradicional em pequenas propriedades, poses, acampamentos, assentamentos, reassentamentos e as políticas públicas, resultantes da luta dos movimentos socioterritoriais. Dentre as conquistas, destacam-se, à conquista da Universidade Federal da Fronteira Sul (UFFS). Uma Universidade Federal dentro de um Assentamento do MST. Essa luta, de certa forma, constituiu uma base que possibilitou a inserção dede muitos grupos, na luta pela universidade, inicialmente o movimento Pró-Universidade Popular.

[...] esse debate iniciou-se ainda no primeiro semestre do ano de 2005, intensificando-se com reuniões periódicas de um coletivo com representações das prefeituras de Porto Barreiro, Rio Bonito do Iguaçu, Nova Laranjeiras, Candói e Laranjeiras do Sul e representantes dos movimentos sociais e entidades citados acima. No primeiro semestre de 2006, porém, a partir de articulações com representantes da Via Campesina, observou-se que no Rio Grande do Sul e em Santa Catarina também acontecia forte mobilização em torno da conquista de uma universidade federal pública e gratuita para a mesorregião da grande fronteira do Mercosul. Optou-se então por agregar estes esforços em torno do movimento pró-universidade nos três Estados do Sul, compondo assim um movimento maior e mais completo (MOHR, 2012, p.797).

Denota-se nessa conquista a correlação de força que nesse momento histórico estava mais fortalecida em virtude da pressão, da luta, da organização dos movimentos no Território. Esse momento histórico da última década do século passado e primeira década deste século, reuniu diferentes sujeitos coletivos do campesinato e da agricultura familiar como: O Conselho de desenvolvimento Territorial (CONDETEC), Associação dos prefeitos da Cantuquiriguaçu, o Movimento Sem terra (MST), Movimento dos Pequenos Agricultores (MPA), Movimento dos Atingidos por Barragens (MAB), Sindicados dos Trabalhadores Rurais (STR's), Cooperativa de Leite da Agricultura Familiar (CORLAFES), Federação dos Trabalhadores na Agricultura Familiar (FETRAF-SUL), Casas Familiares Rurais, Centro de Desenvolvimento Sustentável e Capacitação em Agroecologia (CEAGRO), Quilombolas, lideranças Indígenas, dentre outros. A Educação entra no bojo da luta 
pela terra, ampliando espaços. O que fica caracterizado, é o fato de o território ser, eminentemente camponês, o movimento de luta por políticas públicas tem essa característica, contrário ao modelo hegemônico de produção do agronegócio, por mais que este esteja imbricado nas relações de produção no território.

[...] temos, então, uma disputa territorial entre capital e campesinato. As propriedades camponesas e capitalistas são territórios distintos, são totalidades diferenciadas, nas quais se produzem relações sociais diferentes, que promovem modelos divergentes de desenvolvimento. Territórios camponeses e territórios capitalistas como diferentes formas de propriedades privadas disputam o território nacional (FERNANDES, 2008, p. 280).

O território é marcado pela luta entre o campesinato, da agricultura familiar camponesa de produção de alimentos com a agricultura capitalista de expropriação, de extração, de retirada das riquezas do território, concentra as riquezas e terras nas mãos das oligarquias locais e agora afirmação dessa agricultura capitalista, concentradora e de monocultoras em propriedades do agronegócio.

\section{O TERRITÓRIO CANTUQUIRIGUAÇU: CRIAÇÃO E RECRIAÇÃO CAMPONESA}

O território possui uma área de $13.986,40 \mathrm{~km}^{2}$, com uma população total de 232.519 , sendo 125.060 , ou seja, $53,78 \%$ de população urbana e de 107.459 , ou seja, $46,22 \%$ de população rural, sendo que são 4.264 famílias de assentados em 50 assentamentos, em uma área de 96800 hectares de assentamentos. 
Imagem 01: Território da Cantuquiriguaçu
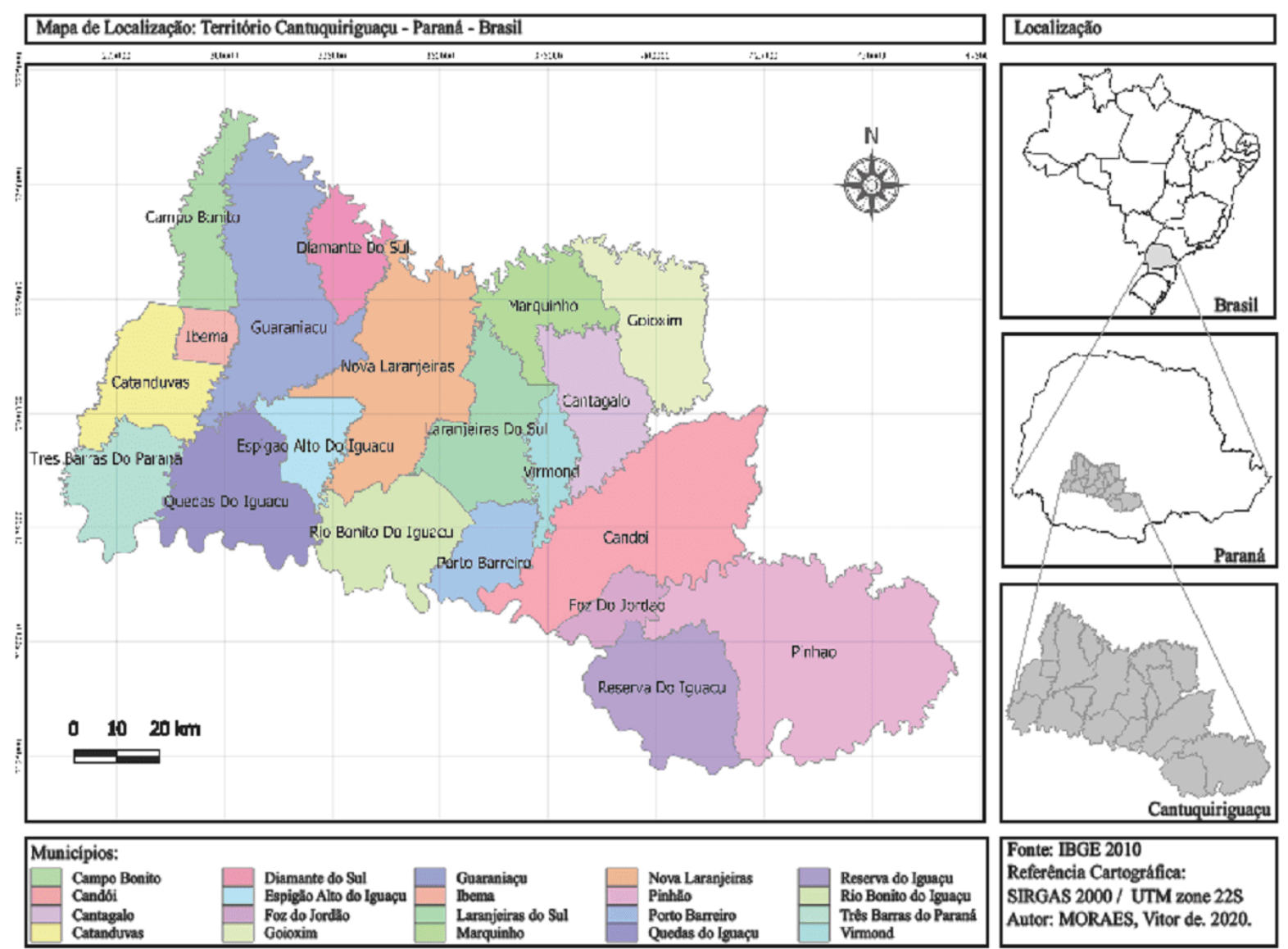

Fonte: IBGE, 2010. Autor: MORAES, Vitor de. 2020.

O "Território é o lugar em que desembocam todas as ações, todas as paixões todos os poderes, todas as forças, todas as fraquezas, isto é onde a história do homem plenamente se realiza a partir das manifestações de sua existência" Santos (2002, p. 9). O território permite apresentar o indivíduo, o grupo, a comunidade a sociedade em intrínsecas relações, contradições e em múltiplas dimensões mensuradas na produção da vida individual e ou coletiva. O conceito de território enquanto governança, foi utilizado no trabalho para definir a escala e o espaço da pesquisa, o território Cantuquiriguaçu da mesorregião centro do Estado do Paraná. Formado por um conjunto de municípios e que em 2009 foi denominado de Território da Cidadania.

O Estado apresenta políticas públicas com a finalidade de suavizar a condição de pauperização das famílias e ao mesmo tempo estimular a produção de mercadorias através da melhora da eficácia produtiva, que 
teoricamente reduziria a pobreza. Trata-se, na verdade, de medidas despolitizadoras, que naturalizam a pobreza, desconsideram o processo histórico de constituição dos territórios com suas assimetrias de poder, relações de clientelismo e patrimonialismo constituídas e, em alguns casos, reforçam esta ordem (ROOS, 2015, p.142)

Nessa visão as políticas nos territórios da cidadania seguiam a mesma cartilha dos organismos internacionais sem uma perspectiva emancipatória e apenas inserir a população economicamente ativa no mundo do trabalho capitalista. Essas políticas públicas não mechem com as estruturas que alicerçam a sociedade e servem para amenizar os conflitos entre as classes.

A luta dos camponeses no território é histórica e se acentua nos anos de 1990, em que os latifúndios grilados ao longo da histórica, começam a ser ocupados pelos Camponeses Sem Terra do MST e outros movimentos, bem como os atingidos por barragens, construídos nas últimas décadas do século passado lutam pelas pelos seus reassentamentos. De um lado temos os camponeses na luta pela terra, por sonhos e significados e de outro o desenvolvimento das conflitualidades na luta de classe pelo avanço do capital na agricultura por meio de modo de produção capitalista por meio do modelo do agronegócio. O território Cantuquiriguaçu, agrega a maior reserva indígena do estado, dos povos Kaingang e Guarani, o maior assentamento de trabalhadores rurais sem terra da América Latina, quatro grupos Quilombolas e mais de $80 \%$ das propriedades rurais do Território são de agricultura familiar. O Território possui em seu espaço sete usinas hidrelétricas. Os vinte municípios que integram este Território apresentam baixíssimos índices de Desenvolvimento Humano. Esta constatação e o alto índice de pobreza e desigualdade social levaram as lideranças do território a elaborar em 2003 o Plano diretor como o objetivo de desenvolver o território. 15 municípios apresentavam em 2003, mais de 20,0\% das pessoas abaixo da linha da pobreza, sendo que a taxa de pobres era de (24,69\%) do total de 62.474 famílias, 26.159 eram consideradas pobres com renda per capita inferior a 1/2 salário mínimo. Outro dado era do esvaziamento da população jovem que deixava o território em busca de trabalho em grandes centros e capitais. Nesse período também foi organizado o Conselho de Desenvolvimento do Território Cantuquiriguaçu (CONDETEC), que integrava 44 entidades representantes da sociedade civil e poder 
público. Esta instancia tinha como atribuições, ser consultiva e deliberativa de projetos, e ações que visassem o desenvolvimento coletivo do Território.

Em 2008, por determinação do Ministério do Desenvolvimento Agrário (MDA), O Território passou a ser intitulado de Território da Cidadania[3], segundo proposta política do governo Federal, com objetivo segundo governo da época, priorizar políticas nos territórios mais pobres do país. Esses territórios "criados" com propósito de governanças levaram em consideração territórios vividos de camponeses, indígenas, quilombolas, acampados, assentados e demais camponeses. Neste aspecto caracterizam-se pela questão eminentemente social, econômica cultural e rural. Sendo o rural o que o mais caracteriza aqui destacado como espaço e território camponês.

Um território rural se define por sua identidade social econômica e cultural com os seguintes requisitos: Conjunto de municípios com até 50 mil habitantes; densidade populacional menor que $80 \mathrm{hab} / \mathrm{Km}^{2}$; organizados em territórios rurais de identidade (...) foram definidos os seguintes critérios técnicos: menor IDH; maior concentração de agricultores familiares e assentamentos da Reforma Agrária maior concentração de populações quilombolas e indígenas; maior número de beneficiários do Programa Bolsa Família; maior número de municípios com baixo dinamismo econômico; maior organização social; pelo menos um território por estado da federação. Até 2010 serão 120 territórios atendidos (MDA, 2008).

Para organizar o processo pensado de desenvolvimento territorial, as representações dos coletivos do território, sejam coletivos organizados em movimentos, associações, cooperativas, igrejas dentre outros coletivos, da sociedade civil, construíram um plano diretor, como instrumento de orientação das políticas públicas O Plano Diretor para o Desenvolvimento da Cantuquiriguaçu definiu dez diretrizes como o objetivo estratégico de promover o desenvolvimento do território Cantuquiriguaçu.

Resgate da cidadania e garantia de acesso às políticas públicas, Geração de postos de trabalho e renda, Educação e alfabetização de jovens e adultos, Capacitação em todos os níveis e setores, Atração e retenção na região de profissionais das mais diversas áreas. Integração intersetorial dentro dos municípios e na região, parcerias e consórcios intermunicipais, parcerias com entes externos à região e fomento à agro industrialização na região. Otimização no uso da infraestrutura e 
recursos regionais como ferrovia, usinas, lagos e BRs (MORAES, 2013, p. 55, grifos nossos).

\section{DADOS DA REALIDADE QUE REAFIRMAM O CAMPESINATO NO TERRITÓRIO CANTUQUIRIGUAÇU}

Apresentamos os dados, destacando a importância do campesinato, de modo que a luta e a resistência passam a serem cruciais. O campesinato representa a produção de alimentos, alimentos saudáveis, a garantia do trabalho familiar e a geração de riquezas que está representada no gráfico abaixo, de onde elas são provenientes.

Gráfico 1 - Origem das riquezas geradas no território Cantuquiriguaçu.

\section{Origem das riquezas geradas no território Cantuquiriguaçu - 2010}

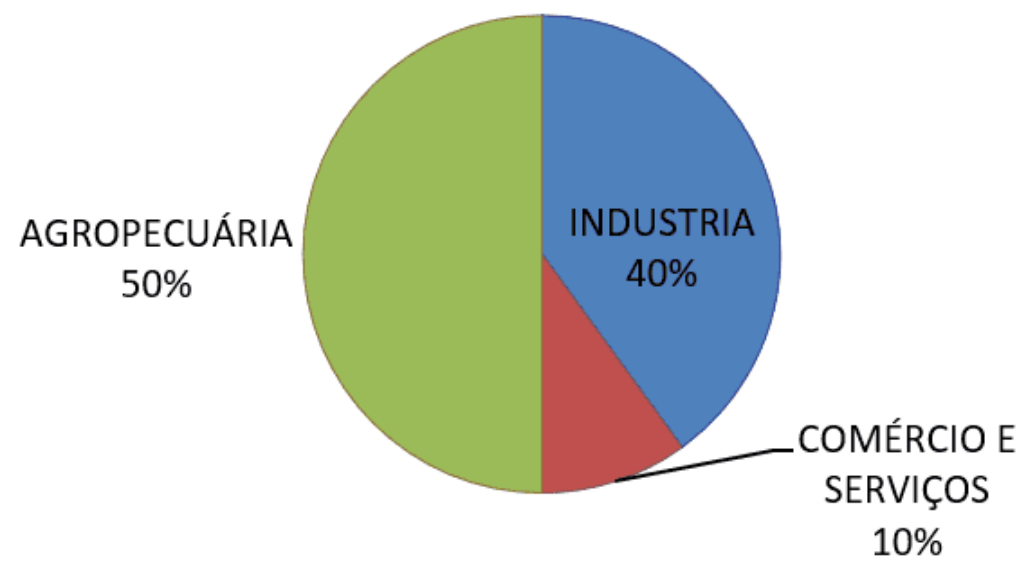

Fonte: IBGE, 2010. Organizado pelo autor, 2019.

O gráfico acima destaca que as riquezas geradas no território têm suas origens na agropecuária, em que, sem separar a produção camponesa da produção do agronegócio, demonstra a força ativa, a participação dos sujeitos que estão no campo. Por hora neste trabalho destacamos o protagonismo do campesinato nesses índices. $\mathrm{O}$ que muitas vezes fica velado esses valores porque quem contabiliza no final a 
produção camponesa é o agronegócio e a outra parte da produção camponesa é para sua soberania alimentar e autonomia como camponês.

São 4.426 famílias assentadas que representam $21 \%$ dos agricultores familiares do Território com $30 \%$ da área, tendo em média 22 ha de área por estabelecimento familiar. Uma das maiores áreas reformadas da América latina. Os assentados,conquistaram a terra na luta organizados, principalmente pelo MST. No movimento de reterritorialização por meio de assentamentos na luta pela terra.

Outro elemento a ser considerado é que o território Cantuquiriguaçu conseguiu manter um alto nível de população rural, em virtude da luta dos movimentos socioterritoriais, com a conquista de 50 assentamentos. No território vivem camponeses tradicionais Vivem em pequenas propriedades, são donos ou não de terras, arrendatários, parceiros, meeiros, assalariados permanentes e ou temporários, agregados, chacareiros e posseiros. O território Possui 20.528 famílias de agricultores familiares. Salientemos que neste dado, está o conjunto dos camponeses destacados acima. O termo Agricultura familiar aqui é do sujeito camponês que tem vínculo com a terra e a base é o trabalho familiar seu modo de vida e sua cultura. Termo que foi incorporado as políticas públicas em 2006. LEI № 11.326. Estabelece as diretrizes para a formulação da Política Nacional da Agricultura Familiar e Empreendimentos Familiares Rurais. Não detenha, a qualquer título, área maior do que 4 (quatro) módulos fiscais. Em média no território de 72 há 4 módulos fiscais.

O território possui Reassentados, são atingidos por Barragens, em partes organizados no Movimento dos Atingidos por Barragens (MAB) e outros não são organizados. No território são reassentados pelo Projeto de Reassentamento de Atingidos por Barragens (PRB). Acampados "Sem Terra", sujeito coletivo vinculado a um movimento. Também tem alguns acampados sem terra, não vinculados a nenhum movimento socioterritorial. Os Ilheus,

(...) Foram trazidos em ocasião da construção da Usina Hidrelétrica de Itaipu. O ilhéu tem como característica marcante de sua identidade a necessidade de viver próximo dos corpos d água. Eles trabalham com a agricultura, porém, na pesca está uma de suas principais atividades. Isso 
implica em uma realidade que é diferente da agrária ou urbana. A pesca é uma atividade para produção da existência, não imprime racionalidade capitalista. Deste modo, observa-se que os ilhéus possuem um modo de viver e produzir próprio, as relações desenvolvidas nos territórios demonstram uma identidade que o diferencia até mesmo de outros camponeses. (COCA, 2016, p. 118)

Os Quilombolas e Remanescentes de quilombos estão em quatro comunidades, localizadas nos municípios de Candói, Reserva do Iguaçu e Pinhão. No município de Candói são três comunidades quilombolas certificadas: a de Despraiado, a Vila Tomé e a do Cavernoso. 406 pessoas distribuídas em 75 famílias. Em Reserva do Iguaçu, na comunidade do Barranco, são aproximadamente 20 famílias acampadas à espera de uma decisão judicial quanto à disputa pela área "Fundão", da Fazenda Capão Grande, hoje sob a posse de uma grande cooperativa agrícola. Demais sujeitos da comunidade, mais de trezentas famílias, estão espalhadas nas periferias das cidades de Guarapuava e de Pinhão. O território possui a maior terra indígena do Paraná, a "Terra Rio das Cobras", com a presença das etnias Kaingang, Guarani e Xeta e uma população Indígena acima de 3.000 habitantes, localizadas nos municípios de Nova Laranjeiras e Espigão Alto do Iguaçu, com área de 18.681,98 ha.

O Censo Agropecuário 2017 (IBGE, 2018) contou 4,9 milhões de estabelecimentos agropecuários que perfazem 350 milhões de hectares. Os cálculos do Índice de Gini para a terra no Brasil figura sempre acima de 0,8006, o que indica uma grande concentração fundiária. Os dados do Censo Agropecuário 2017 mostram que os estabelecimentos com mais de 1.000 hectares, que representam 1,01\% dos estabelecimentos agropecuários brasileiros, concentram $47,5 \%$ das terras. A área média desses estabelecimentos é de 3.272,4 hectares. (GIRALDI,2019, p.119).

O que caracteriza a lentidão dos processos de desapropriação e o cerne da concentração de terra e o absoluta descaso para novos georreferenciamentos e o reordenamento agrário, para verificar se de fato não existe "terras escondidas", griladas em granjas e fazendas. 
Gráfico 2: Quantidade de estabelecimentos: Brasil - Paraná - Cantuquiriguaçu

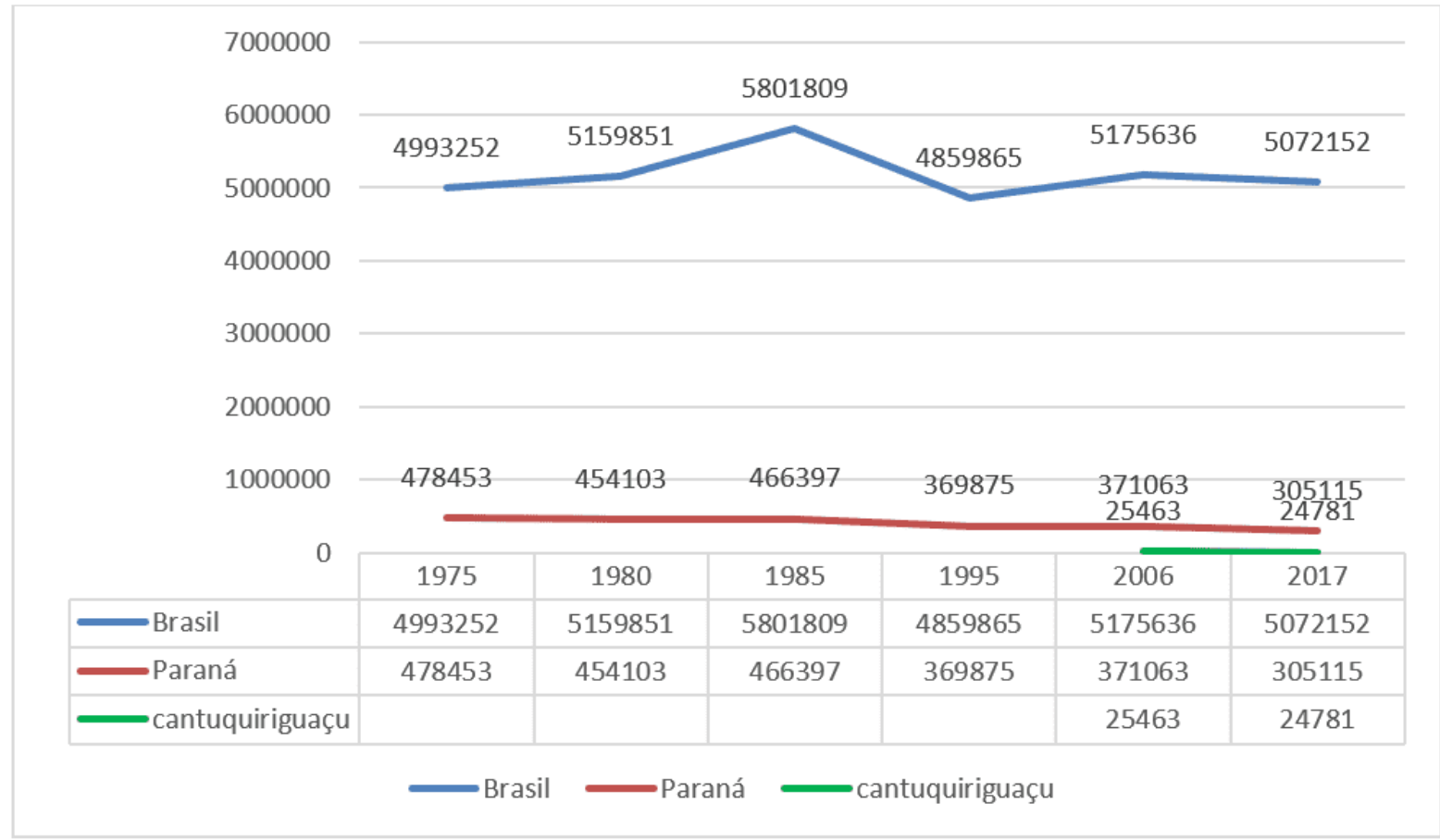

Fonte: IBGE, Censos Agropecuários 1975/2017. Organizado pelo autor, 2019.

Os gráficos 2 e 3 a redução do número de estabelecimentos da agricultura familiar e camponesa. Explicitam a dura realidade da concentração da terra para a produção apenas de commodities. Reduz drasticamente a quantidade de propriedades que podem produzir de forma familiar, poli cultivos, alimentos saudáveis, agroecológicos.

há um grande número de estabelecimentos agropecuários cuja área é extremamente pequena, a exemplo dos estabelecimentos com menos de 5 hectares, que mesmo sendo $37,8 \%$ dos estabelecimentos, ocupam tão somente $0,98 \%$ da área total. Também há aqueles produtores que sequer possuem área para produção, contabilizados em 76.671 no Censo Agropecuário de 2017 (GIRARDI, p.120).

No Brasil uma redução de $2 \%$ na Cantuquiriguaçu segue esse valor de 2,67\%, porém de forma geral no Paraná foi altíssima chegando a 17,77\%. Mostrando um alto nível de concentração de terras e riquezas. Características de uma elite agrária extremamente conservadora. 
Gráfico 3: Quantidade de estabelecimentos (redução) 2006-2017(\%)

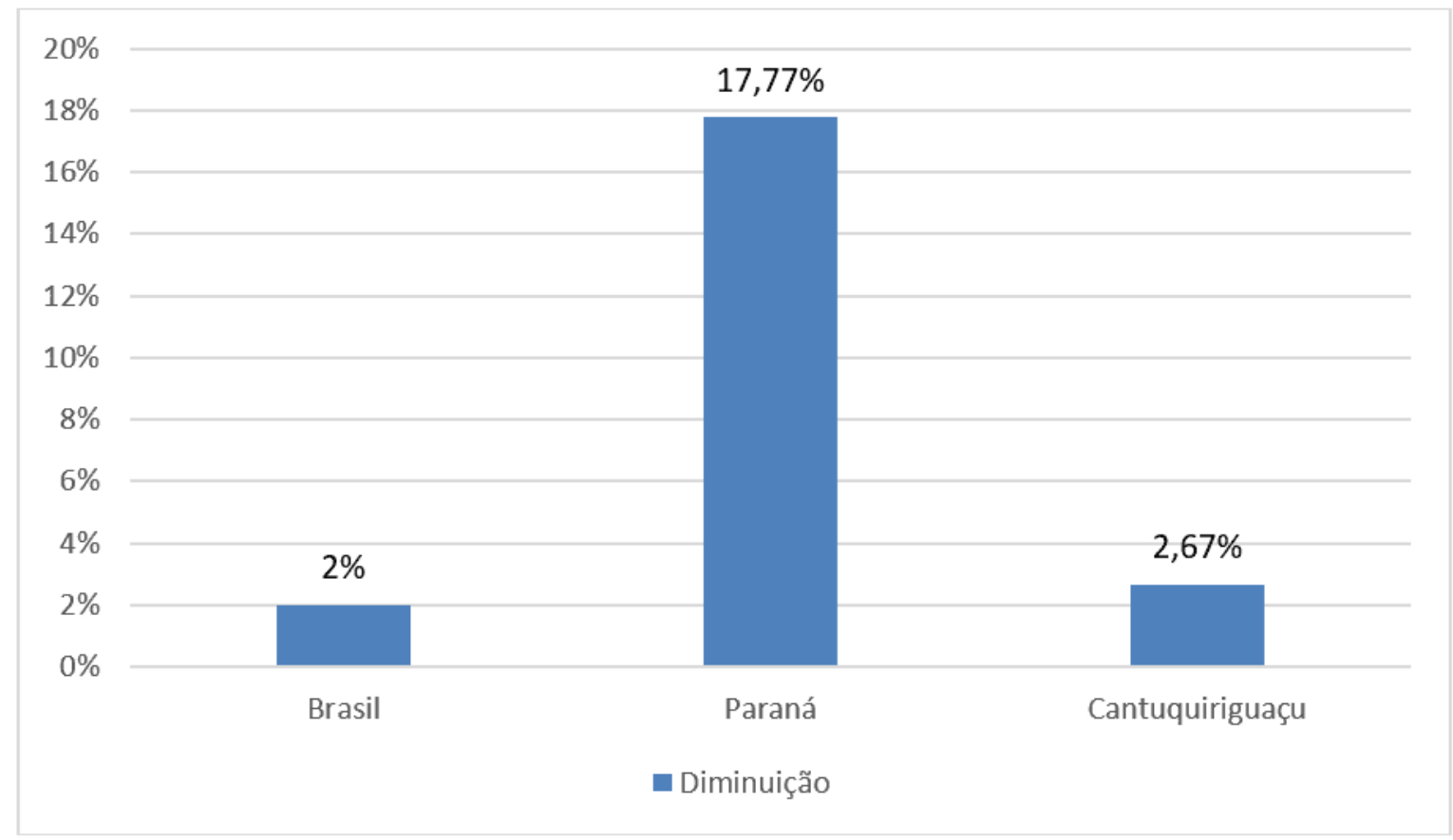

O gráfico abaixo demonstra a alta taxa de lavouras temporárias como soja e milho tanto no Território quando no Paraná. O dobro que o Brasil no Território e praticamente o triplo a nível estadual. 
Gráfico 4: Utilização da área dos estabelecimentos(\%)

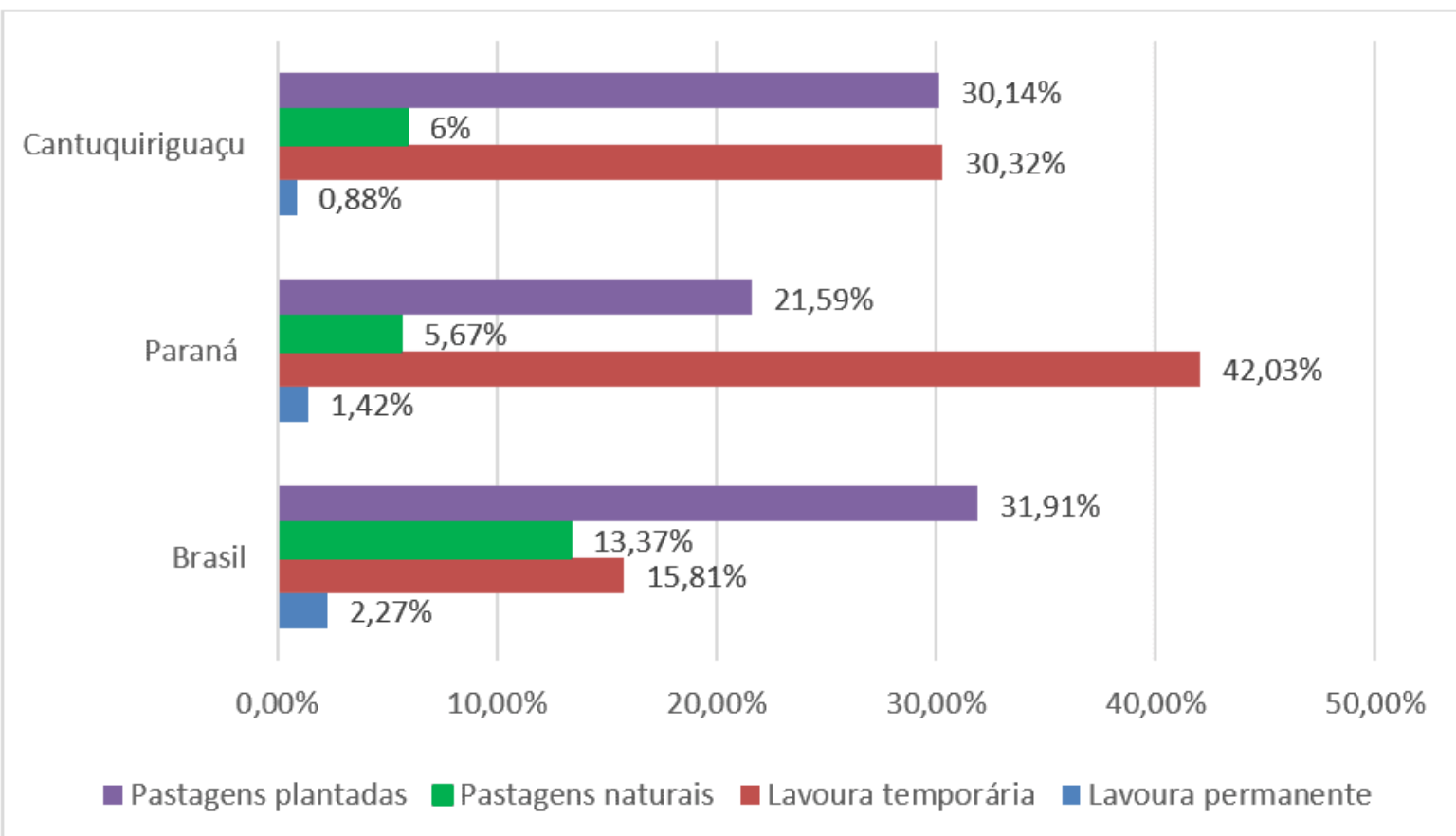

Fonte: IBGE, 2019. Organizado pelo autor, 2019.

Fica explicito o modelo de agricultura do agronegócio. Produção de soja, milho, pecuária. No Território Cantuquiriguaçu em virtude do grande número de pequenas propriedades o avanço das fazendas é de forma geral, mais baixo que no Brasil.

Há muita terra subutilizada (a própria pastagem como é manejada no Brasil é uma forma). O avanço sobre as florestas e terras indígenas não são mais do que estratégias de produção de fazendas; o objetivo com isso é produzir terras para vendê-las no futuro. É a continuação da apropriação privada concentradora de terras no Brasil. (GIRARDI, 2019, p. 133).

No entanto é notório no Território Cantuquiriguaçu a presença da população rural. Os dados demonstram que é um território eminentemente camponês. O que se articula com os dados da produção e ocupação em notoriedade e importância. 
Gráfico 5: População urbana e rural- 2000 e 2010(\%).

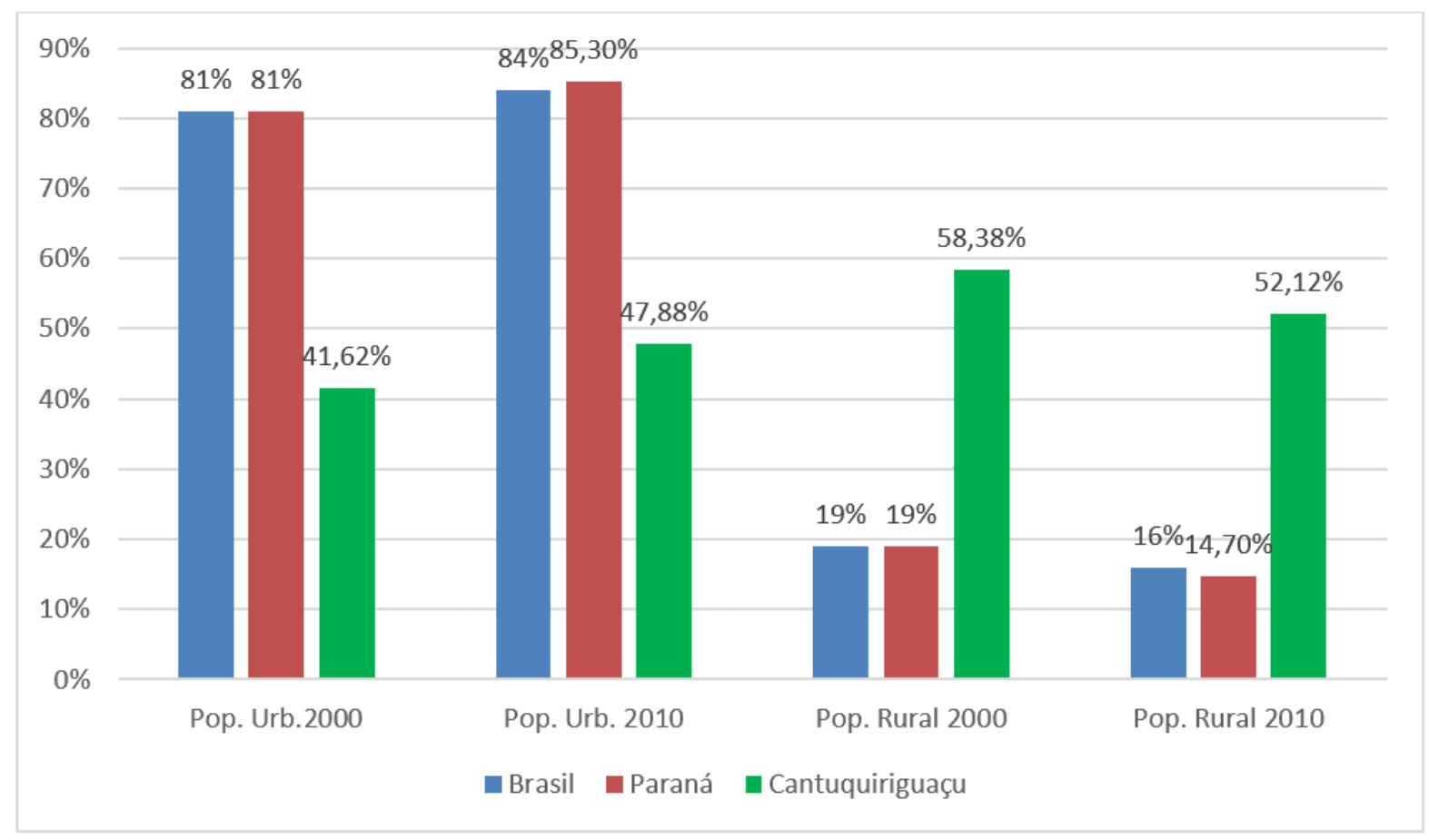

Fonte: IBGE, 2019. Organizado pelo autor, 2019.

Os dados do gráfico acima demostram que mesmo com todo o fetiche da urbanização, da chamada permanente dos filhos do camponeses para serem trabalhadores baratos nas cidades em serviços secundários, mesmo com a falta de políticas públicas coerentes com o desenvolvimento do campo, o Território Cantuquiriguaçu, por meio da luta dos camponeses, pelo seu modo de vida, organizados em MSPC ou não, continuam a criar e recriar o campesinato. 
Gráfico 6: Pessoal ocupado no campo (número de pessoas)

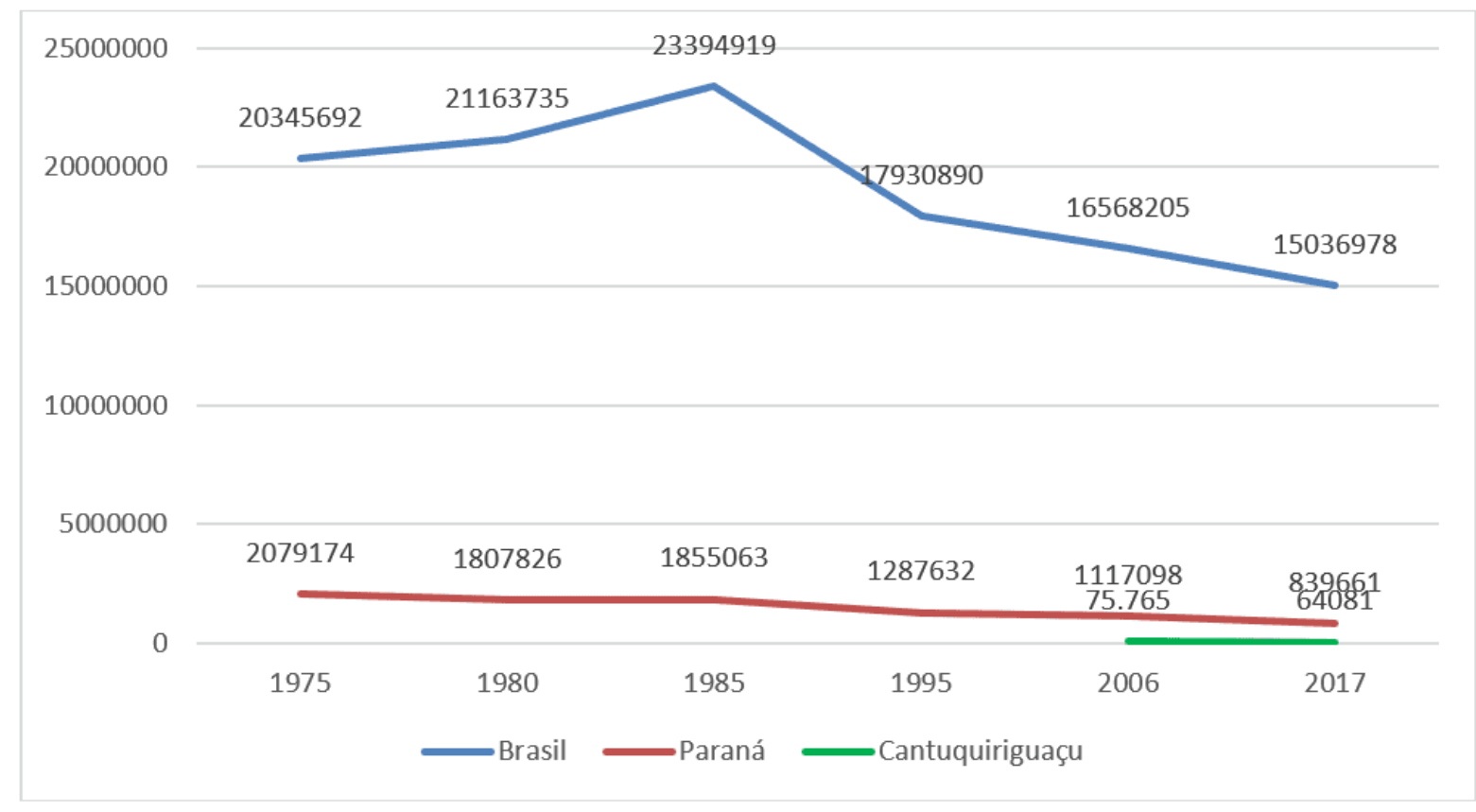

Fonte: IBGE, 2019. Organizado pelo autor, 2019.

Nota-se uma acentuada redução do pessoal ocupado no campo. No entanto se comparado ao Estado do Paraná, a redução foi menor em quase 10\% e em relação ao Brasil uma redução de $5 \%$ a mais.

Em relação a financiamento para a produção e infra-estrutura, ainda é gritante tanto em nível de país, estado e Território. Porém por ser um território com grande número de pequenas propriedades o índice é ruim, mas considerável. 
Gráfico 07: Obtenção de financiamento(\%)

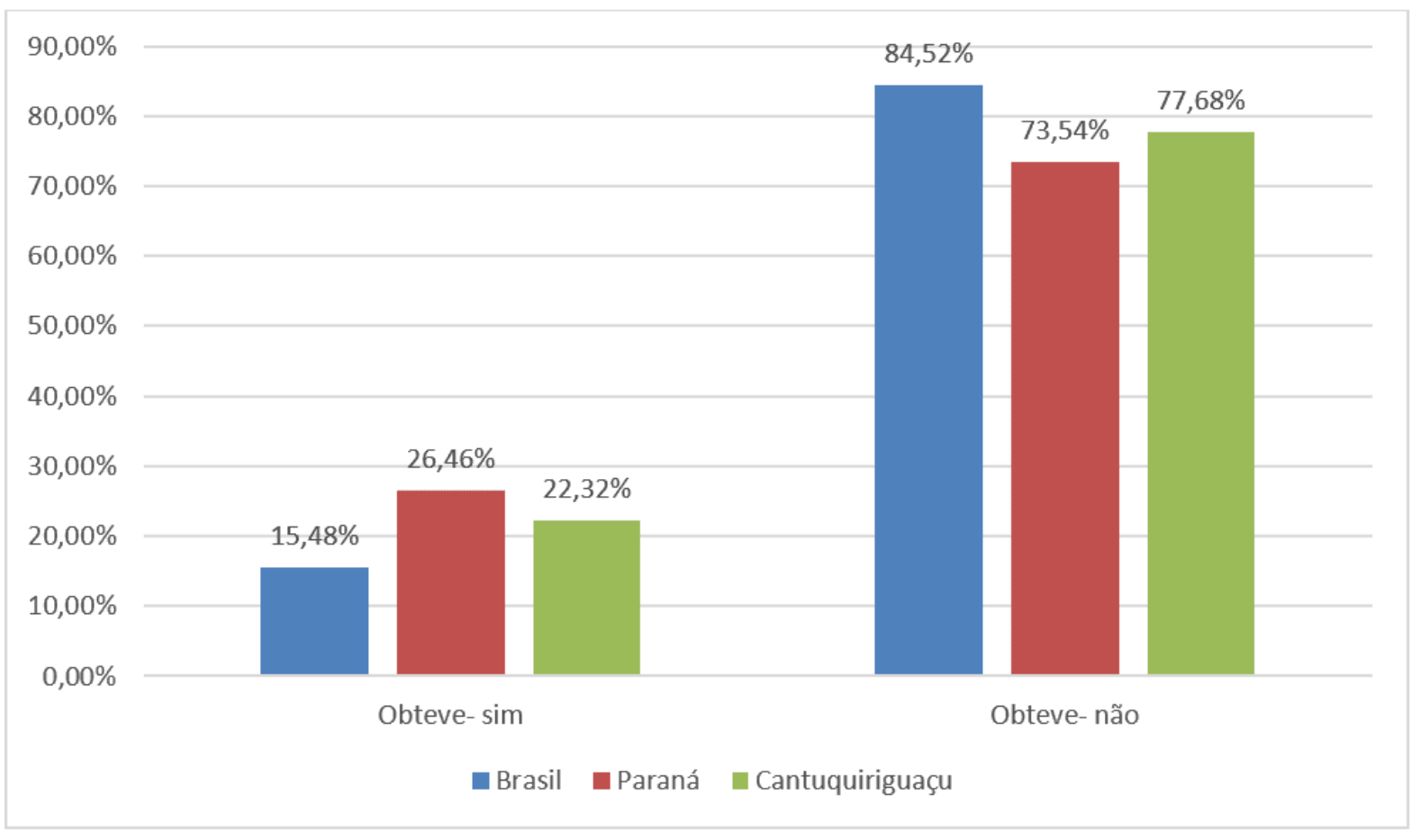

Fonte: IBGE, 2019. Organizado pelo autor, 2019.

O gráfico acima, pode ser de extrema empiria, no entanto se considerarmos as políticas públicas efetivadas no território na primeira década deste século, para a classe pobre, em que incluem o conjunto dos camponeses e demais trabalhadores que receberam políticas de transferência de renda, o gráfico passa a ser extremamente significativo. Por quê? Porque percebe-se a necessidade da continuidade e o reconhecimento da importância das mesmas, embora, muitas apenas momentâneas já outras estruturais como é o caso da Universidade Federa da Fronteira Sul (UFFS) em um Assentamento, com extensão, pesquisas e formação para o desenvolvimento do Território. Programas de assistências técnica em agroecologia (CEAGRO), dentre outros.

Outra dimensão crucial para o Território é a necessária sucessão familiar, em que o gráfico 8 , abaixo, destaca a baixa presença de jovens no campo. No entanto consideramos que no Território Cantuquiriguaçu é maior, mesmo com a falta de 
incentivos, de políticas de desenvolvimento territorial em agricultura, Educação e qualidade de vida.

Gráfico 8: Sucessão familiar em relação a gestão de estabelecimentos - Jovem com menos de 30 anos (\%).

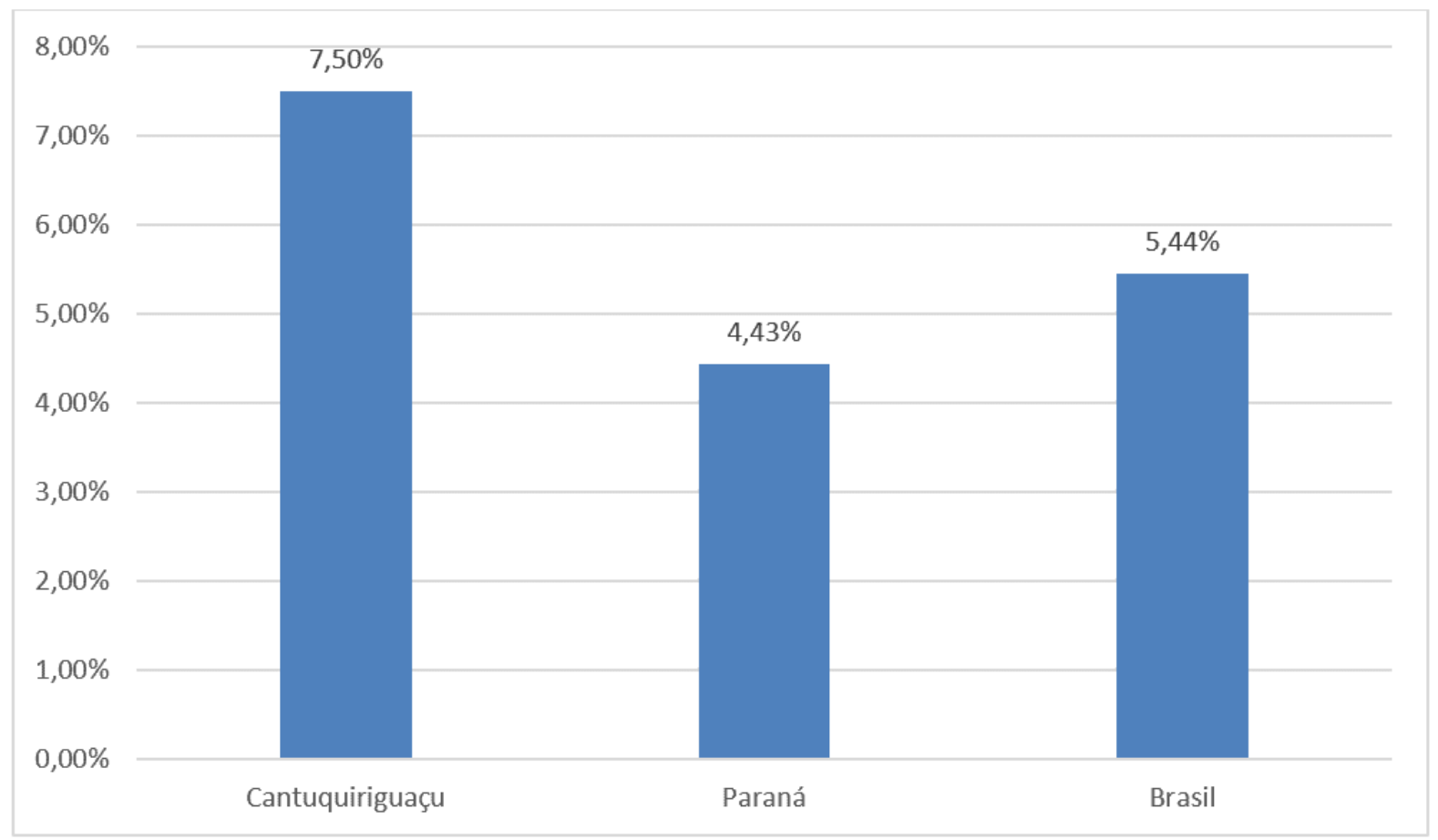

Fonte: IBGE, 2019. Organizado pelo autor, 2019.

Observando-se o gráfico é possível conclui é preocupante a falta da sucessão familiar no campo, No entanto, e há um número maior de estabelecimentos comandados por jovens na região da Cantuquiriguaçu. Fica evidente a necessidade de políticas públicas que contribuem, incentivem a permanência do jovem no campo com renda e qualidade de vida.

\section{CONSIDERAÇÕES}

Mesmo com poucas políticas públicas de desenvolvimento territorial, o espectro positivo, que ronda a realidade do Território Cantuquiriguaçu é a presença permanente dos Movimentos Socioterritoriais como MST, MAB, MPA, o Movimento Sindical camponês pelos Sindicatos da FETRAF, CONTAG, e uma gama de 
representantes que articulam um desenvolvimento coletivo, moderno, agrecológico, progressista do Território. Isso constatado, não como pensamento ingênuo. Consideramos por outro lado, o avanço permanente do modelo de agricultura capitalista do agronegócio. $\mathrm{O}$ agronegócio tem poder financeiro e de mídia, o que apresenta esse modelo como único escondendo a realidade camponesa de luta e de resistência.

As grandes "cooperativas do agronegócio" buscam alinhar o agricultor camponês familiar ao projeto da agricultura capitalista pelas monoculturas, mercantilização total de sua produção, pela integração da produção e comercialização como é o caso do leite e do fumo.

Por outro lado, ficou evidente na pesquisa, o protagonismo dos movimentos socioterritoriais e do CONDETEC, como proponentes de políticas públicas junto às instâncias governamentais na primeira década deste século. Também, muito foi às críticas em relação a poucas políticas e a razoável intervenção na realidade da população do Território Cantuquiriguaçu. No entanto ao buscar compreender o momento presente de negação total de políticas de desenvolvimento Territorial, percebemos a significância dos avanços da primeira década do século.

Este trabalho filia-se na interpretação e na concordância, da importância das políticas públicas de desenvolvimento que ocorreram na primeira década deste século. De acordo com o "Relatório de ações do MDA", muitos projetos desenvolvidos e efetivados no Território foram financiados com recursos do Programa de Apoio ao Desenvolvimento Sustentável de Territórios Rurais (PRONAT), programa de Apoio a Projetos de Infraestrutura e Serviços dos Territórios (PROINF) dentre outros, de 2003 até 2010. De 2003 a 2010, elo PRONAT, somaram-se um montante de $R \$$ 6.510.209,16, distribuídos e utilizados para o fortalecimento e estruturação de instituições da sociedade civil e agricultura camponesa e familiar e na geração de renda através do fortalecimento dos sistemas produtivos. O Programa de Aquisição de Alimentos (PAA), adquiriu produtos da agricultura familiar, da reforma agrária, de povos e comunidades tradicionais, essencial para Alimentar sujeitos atendidos pela rede socioassistencial, pública e filantrópica. Para a Cantuquiriguaçu - PR, como 
exemplo, em 2013, a meta foi atender a 254 famílias com um investimento de $\mathrm{R} \$$ 977.147,84 no Território Cantuquiriguaçu. O programa Saberes da Terra disponibilizou para o Território em 2006, $R \$ 800.000,00$, para a formação e qualificação de 400 camponeses (as). Também teve um Investimento de alguns milhões, para a construção da UFFS, manutenção, salários dentre outros o que aqueceu o mercado imobiliário e de consumo e serviços em geral, principalmente no município de Laranjeiras do Sul, que viu sua população aumentar significativamente bem como a qualificação de sua população e do Território. O território possuem uma das maiores áreas reformadas da América latina, bem como uma gama de diversidade de sujeitos no campo. Acampados, Assentados, Reassentados, Quilombolas, Camponeses tradicionais, Ilhéus, Indígenas dentre outros.

No entanto, é notório a ignorância da elite local, em relação às diversas políticas públicas de desenvolvimentos conquistadas e as demais que ainda poderão desenvolver o território caso sejam efetivadas. Destacamos como relevante, dentre as várias políticas, a Universidade Federal da Fronteira Sul (UFFS), dentro de um assentamento da reforma agrária com cursos diversos na perspectiva do desenvolvimento territorial e os projetos vinculados aos movimentos e a luta pela terra. "ninguém ama o que não conhece", e a elite insiste em não conhecer, em manter o preconceito, mesmo sabendo que é ela, que por fim, se apropria das riquezas conquistadas pelo povo, organizados em movimentos. Os camponeses (as), organizado (as) nos movimentos ou fora deles, numa prática de relações sociais territorialmente, realizam um conjunto de ações concretas, inovadoras, vivificadas, que permitem sua existência e a demonstração de seu conhecimento, e que isso acaba incomodando a elite dominante que não the reconhece como sujeito e classe social.

\section{REFERÊNCIAS}

ABREU, Alcioly Therezinha Gruber. A posse e o uso da terra. Modernização agropecuária de Guarapuava. Dissertação (Mestrado em História). Universidade Federal do Paraná. Curitiba, 1981. 
CANTUQUIRIGUAÇU, Associação dos Municípios da Cantuquiriguaçu. Plano diretor para o desenvolvimento dos municípios da Cantuquiriguaçu. Laranjeiras do SulPR, 2003.

COCA. Estevam Leopoldo de Freitas. A diversidade da reforma agrária no Território Cantuquiriguaçu - PR. Uma discussão sobre a tipologia dos assentamentos rurais.|Ed. Verlag. 2016.

FERNANDES, Bernardo Mançano. "Educação do Campo e Território Camponês no Brasil."in: SANTOS, Clarice Aparecida. (Org.) Por uma educação do campo; Campo - Políticas Públicas. Brasília: Incra/MDA, 2008.p.39-66.

GIRARDI, Eduardo Paulon. Questão agrária, conflitos e violências no campo brasileiro. Revista NERA, v. 22, n. 50, p. 116-134, 2019.

IBGE - Instituto Brasileiro de Geografia e Estatística. Censo Agropecuário 2018. Rio de Janeiro: IBGE, 2017. Disponível em: www.sidra.ibge.gov.br

IPARDES, Instituto Paranaense de Desenvolvimento Econômico e Social. Diagnostico

socioeconômico do Território Cantuquiriguaçu: 1a fase caracterização global. Curitiba: IPARDES, 2007.

MDA. Ministério do desenvolvimento agrário. Territórios da Cidadania. 2008. Disponível em: https://www.embrapa.br/documents. Acesso em 01-09-2019.

MOHR, Naira Estela Roesler (Org.). A expansão das fronteiras da educação pública superior: uma análise da experiência da Universidade Federal da Fronteira Sul em Laranjeiras do Sul. Revista Brasileira de Estudos Pedagógicos, Brasília, v. 93, n. 235, p. 791-817, set./dez. 2012.

MORAES, Vitor de. WELCH. Clifford Andrew. A disputa territorial e o controle das políticas no território Cantuquiriguaçu - Estado do Paraná: a participação dos 
movimentos socioterritoriais e o papel do Estado. Revista NERA, n. 27, p. 96-112, 2015.

PONTAROLO, L. P. Francisco das Chagas Lima: a atuação de um padre secular no povoamento dos campos de Guarapuava (1808-1828). 2012. 112f. Dissertação (Mestrado em História), Universidade Federal do Paraná, Curitiba, PR.

ROOS, Djoni. Contradições na construção dos territórios camponeses no Centro-Sul paranaense: territorialidades do agronegócio, subordinação e resistências. UNESP SP. Presidente Prudente: [s.n.], 2015.

SANTOS, Milton. A natureza do espaço. São Paulo: EDUSP, 2002.

\section{APÊNDICE - REFERÊNCIA DE NOTA DE RODAPÉ}

3. Território da Cidadania: o Programa Territórios da Cidadania (PTC), que foi criado pelo Governo Federal brasileiro no ano de 2008 como uma continuidade de políticas públicas de desenvolvimento territorial que vinham sendo aplicadas desde 2003 (MDA, 2008). Fonte: mda.gov.br.

Enviado: Agosto, 2020.

Aprovado: Agosto, 2020. 